\title{
Serum Vitamin D Concentrations and Cognitive Change Over 20 Years: The Atherosclerosis Risk in Communities Neurocognitive Study
}

\author{
Andrea L.C. Schneider ${ }^{a}$ Di Zhao ${ }^{b}$ Pamela L. Lutsey ${ }^{c}$ Rebecca F. Gottesman ${ }^{a}$ b \\ A. Richey Sharrett ${ }^{b}$ Andreea M. Rawlings ${ }^{b}$ Alvaro Alonso ${ }^{d}$ David Knopman $^{e}$ \\ Thomas H. Mosley $^{f}$ Elizabeth Selvin ${ }^{b}$ Erin D. Michos ${ }^{b}, g$ \\ a Department of Neurology, Johns Hopkins School of Medicine, Baltimore, MD, USA; bepartment of Epidemiology, \\ Johns Hopkins Bloomberg School of Public Health, Baltimore, MD, USA; ' ${ }^{C}$ Division of Epidemiology and Community \\ Health, University of Minnesota, Minneapolis, MN, USA; ${ }^{d}$ Department of Epidemiology, Emory University \\ Rollins School of Public Health, Atlanta, GA, USA; ${ }^{e}$ Department of Neurology, Mayo Clinic, Rochester, MN, USA; \\ ${ }^{f}$ Department of Medicine, University of Mississippi Medical Center, Jackson, MS, USA; ${ }^{9}$ Division of Cardiology, \\ Department of Medicine, Johns Hopkins School of Medicine, Baltimore, MD, USA
}

\section{Keywords}

Cognition · Vitamin D · Cohort study

\begin{abstract}
Background/Aims: 25-hydroxyvitamin D (25[OH]D) concentrations have been associated with cognitive decline and incident dementia in elderly populations; however, these relationships are susceptible to reverse causation. Less is known about the association of midlife $25(\mathrm{OH}) \mathrm{D}$ with long-term cognitive decline. Methods: This was a prospective cohort study of 13,044 participants (mean age 57 years at baseline) in the Atherosclerosis Risk in Communities Study. 25(OH)D was measured from serum collected at baseline (1990-1992) using liquid chromatography tandem high-sensitivity mass spectrometry. Cognition was assessed using 3 neuropsychological tests at 3 time points, which were combined into a composite cognitive $Z$-score. Multivariable-adjusted linear mixed-effects models with random intercepts and slopes were used to estimate associations between $25(\mathrm{OH}) \mathrm{D}$ and
\end{abstract}

(c) 2018 S. Karger AG, Basel

E-Mail karger@karger.com www.karger.com/ned cognitive change over 20 years. Results: Compared to persons with sufficient $25(\mathrm{OH}) \mathrm{D}(\geq 30 \mathrm{ng} / \mathrm{mL})$, those with deficient $(<20 \mathrm{ng} / \mathrm{mL})$ and intermediate $(20-<30 \mathrm{ng} / \mathrm{mL}) 25(\mathrm{OH})$ $\mathrm{D}$ concentrations had similar cognitive decline in composite cognitive $Z$-scores (deficient versus sufficient: -0.035 [95\% Cl -0.104 to 0.033 ] and intermediate versus sufficient: -0.029 [95\% Cl -0.080 to 0.023$]$ ). Conclusions: Lower concentrations of $25(\mathrm{OH}) \mathrm{D}$ measured in midlife were not significantly associated with more rapid cognitive decline over a 20-year follow-up period. The results of this prospective study are less susceptible to reverse causation than prior studies.

(c) 2018 S. Karger AG, Basel

\section{Introduction}

Millions of people worldwide are affected by vitamin $\mathrm{D}$ insufficiency and deficiency as defined by 25-hydroxyvitamin D (25[OH]D) concentrations $20-<30$ and $<20 \mathrm{ng} /$ $\mathrm{mL}$ respectively [1]. Low concentrations of $25(\mathrm{OH}) \mathrm{D}$ have 
Fig. 1. Study flow diagram, ARIC study (1990-1992 to 2011-2013).

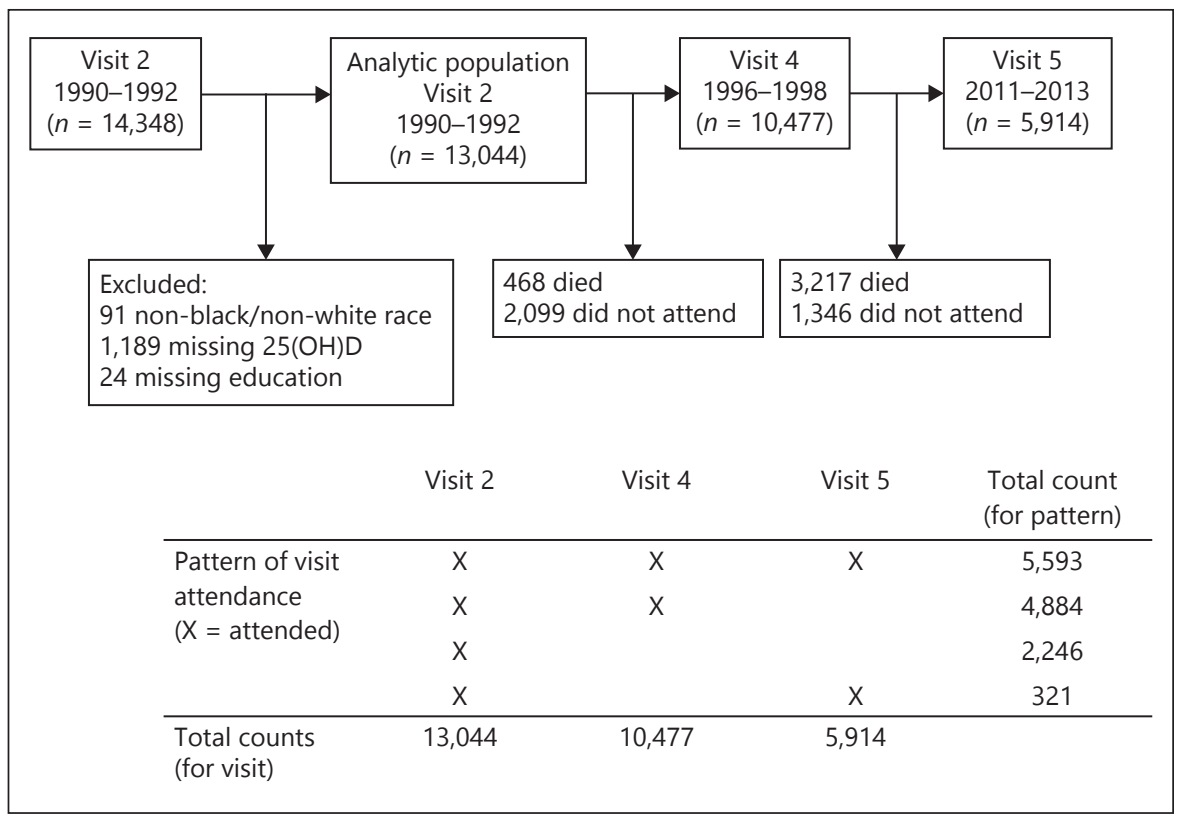

been associated with cognitive decline, mild cognitive impairment, and dementia in prior studies, particularly in those studies performed in elderly populations [2-7]. However, the evidence for an association of low 25(OH) $\mathrm{D}$ with increased risk for cognitive decline over time is inconsistent, with several other prior studies reporting no association [8-12]. Interestingly, the mean age at baseline in most of the studies reporting no associations was substantially lower (mean age 59-63 years followed for a mean of 3-16 years) [8-11] compared to an older mean age in studies that did report associations of low $25(\mathrm{OH})$ $\mathrm{D}$ with increased cognitive decline (mean age $74-80$ years followed for a mean of 2-5 years) [2-7]. This discrepancy in the literature raises the question of reverse causation, whereby older individuals who are more likely to have cognitive impairment and other medical comorbidities are also less likely to have adequate sun exposure outside, which is a major source of vitamin $\mathrm{D}$, and are therefore more likely to have lower concentrations of $25(\mathrm{OH}) \mathrm{D}$ [13]. The possibility of reverse causation suggests that $25(\mathrm{OH}) \mathrm{D}$ concentrations may be a marker of poor health rather than a causative factor in dementia pathogenesis. In order to avoid reverse causation, long-term prospective studies of initially healthy adults who do not have baseline cognitive impairment are needed.

The Atherosclerosis Risk in Communities Neurocognitive Study (ARIC-NCS) provides a unique opportunity to explore the association of $25(\mathrm{OH}) \mathrm{D}$ measured in midlife with cognitive change, since in ARIC, cognitive assessments were conducted at several time points over 20 years of follow-up. We hypothesized that lower concentrations of midlife $25(\mathrm{OH}) \mathrm{D}$ would not be associated with greater 20-year cognitive decline.

\section{Methods}

\section{Study Population}

The ARIC Study is an ongoing, community-based prospective cohort that originally enrolled 15,792 adults aged $45-65$ years in 1987-1989 (visit 1) from 4 US communities (suburbs of Minneapolis, Minnesota; Washington County, Maryland; Forsyth County, North Carolina; and Jackson, Mississippi) [24]. Participants attended up to 4 subsequent visits, which took place in 1990-1992 (visit 2), 1993-1995 (visit 3), 1996-1998 (visit 4), and 2011-2013 (visit 5) respectively. $25(\mathrm{OH}) \mathrm{D}$ concentrations were measured at the 2nd visit (1990-1992), which is the baseline for the present analysis. Cognitive testing was performed at 3 visits: visit 2 (19901992), visit 4 (1996-1998), and visit 5 (2011-2013).

Of the 14,348 participants who attended visit 2 (1990-1992), we excluded 91 non-white/non-black, or black participants from Minnesota or Maryland, 1,189 participants missing 25(OH)D concentrations, and 24 participants missing information on educational attainment, leaving 13,044 included in our analytic population (Fig. 1).

Institutional Review Boards at all participating institutions approved the ARIC Study. All participants provided written informed consent at each study visit.

\section{Measurement of 25-Hydroxyvitamin D Levels and}

\section{Related Biomarkers}

Serum samples were obtained at ARIC visit 2 (1990-1992) and stored at $-70^{\circ} \mathrm{C}$, until $25(\mathrm{OH}) \mathrm{D} 2$ and $25(\mathrm{OH}) \mathrm{D} 3$ concentrations were measured in 2012-2013 using liquid chromatography tan- 
dem high-sensitivity mass spectrometry (Waters Alliance e2795; Waters, Milford, MA, USA) [14, 15]. 25(OH)D2 and 25(OH)D3 were summed up to get the total $25(\mathrm{OH}) \mathrm{D}$ concentration.

$25(\mathrm{OH}) \mathrm{D}$ concentrations have been shown to differ by season [16]. Therefore, we adjusted 25(OH)D for seasonal variation by computing residuals from a linear regression model with $25(\mathrm{OH})$ $\mathrm{D}$ as the dependent variable and the month of visit as the independent variable. The residuals were added back to the mean value to obtain an estimated annual $25(\mathrm{OH}) \mathrm{D}$ value. This adjustment was performed separately for whites and for blacks, as $25(\mathrm{OH}) \mathrm{D}$ concentrations have been shown to vary by race [17]. The estimated annual $25(\mathrm{OH}) \mathrm{D}$ value was used in all subsequent analyses. $25(\mathrm{OH}) \mathrm{D}$ was divided into clinical categories for our main analyses [18]: $\geq 30 \mathrm{ng} / \mathrm{mL}$ (sufficient, reference), 20 to $<30 \mathrm{ng} / \mathrm{mL}$ (intermediate), and $<20 \mathrm{ng} / \mathrm{mL}$ (deficient) [1]. In sensitivity analyses, we also explored the following $25(\mathrm{OH}) \mathrm{D}$ categories: $\geq 20 \mathrm{ng} / \mathrm{mL}$ (reference), 10 to $<20 \mathrm{ng} / \mathrm{mL}$, and $<10 \mathrm{ng} / \mathrm{mL}$.

\section{Measurement of Cognition}

Cognitive function was assessed at visit 2 (1990-1992), visit 4 (1996-1998), and visit 5 (2011-2013) using 3 standard cognitive tests: the delayed word recall test (DWRT) [19], the digit symbol substitution test (DSST) [20], and the word fluency test (WFT) [21] (online supplementary methods; for all online suppl. material, see www.karger.com/doi/10.1159/000490912).

Scores on the DWRT, DSST, and WFT at each visit were transformed to $Z$ scores and standardized to visit 2 by subtracting the participant's test score at each visit from the mean score at visit 2 and dividing by the SD of the visit 2 scores. A composite global cognitive $Z$ score at each visit was calculated by averaging the $Z$ scores of the 3 cognitive tests (DWRT, DSST, and WFT) and was then standardized to visit 2 by using the mean and SD of the composite cognitive $Z$-score at visit 2 . Composite global cognitive $Z$ scores derived using these methods have been used in previous analyses of cognitive change in the ARIC study [22,23]. This composite global cognitive $Z$-score was used as the primary outcome for the present study.

\section{Covariates}

All covariates were assessed at visit 2 (1990-1992), unless otherwise stated. Covariates in our main model (Model 1) included: age, sex, race/field center (Minneapolis, MN-whites; Washington County, MD-whites; Forsyth County, NC-whites; Forsyth County, NC-blacks; Jackson, MS-blacks), education (<high school; high school or equivalent; college, graduate or professional school; assessed at visit 1$)$, body mass index $\left(\mathrm{kg} / \mathrm{m}^{2}\right)$, cigarette smoking (never, former, current), physical activity (score range $1-5$, based on responses to the Baecke Physical Activity questionnaire [25]), and apolipoprotein $\epsilon 4$ genotype ( $0 \in 4$ alleles; $1 \in 4$ allele; $2 \in 4$ alleles).

Model 2 included variables in Model 1 plus potential mediators of the purported association between vitamin $\mathrm{D}$ and cognitive function (systolic blood pressure $[\mathrm{mm} \mathrm{Hg}]$, use of hypertension medications, diabetes [defined by self-reported physician diagnosis, medication use, fasting blood glucose $\geq 126 \mathrm{mg} / \mathrm{dL}$, or non-fasting blood glucose $\geq 200 \mathrm{mg} / \mathrm{dL}$ ], total cholesterol [mg/dL], HDL cholesterol $[\mathrm{mg} / \mathrm{dL}]$ ), use of cholesterol-lowering medications, estimated glomerular filtration rate (calculated using the chronic kidney disease epidemiology collaboration formula [26]), and prevalent coronary heart disease (defined by standardized criteria and physician adjudication [27]). Model 3 included variables in Models 1 and 2 plus biomarkers related to vitamin D metabolism including calcium $(\mathrm{mg} / \mathrm{dL})$, phosphorous $(\mathrm{mg} / \mathrm{dL})$, and PTH $(\mathrm{pg} / \mathrm{mL})$.

\section{Statistical Analyses}

To account for the within-person correlations of test scores arising from the repeated measures over time, linear mixed-effects models with random intercepts and slopes were used to estimate the associations between $25(\mathrm{OH}) \mathrm{D}$ and cognitive change over 20 years. Random effects were assumed to be independent and robust variance estimates were used. Time since baseline (19901992) was modeled using a linear spline with a knot at 6 years (average duration of time between visits 2 and 4). The primary coefficients of interest were the interactions between $25(\mathrm{OH}) \mathrm{D}$ and the time spline terms, which directly address our hypothesis of no difference in cognitive decline $25(\mathrm{OH}) \mathrm{D}$ groups. All models also included interaction terms between each of the covariates and time. In sensitivity analyses, we excluded participants scoring worse than -2 SDs on the baseline composite cognitive $Z$-score to address concerns about possible reverse causation and bias due to floor effects that could occur if participants with preclinical cognitive impairment at baseline were included.

All $p$ values were based on 2 -sided tests. A $p<0.05$ was considered statistically significant. Analyses were performed using Stata SE version 14 (StataCorp, College Station, TX, USA).

\section{Missing Data}

Our primary analyses were performed using multiple imputations by chained equations methods $[28,29]$ with 25 imputations to impute missing covariate and cognitive test data to account for study attrition (see Fig. 1 for patterns of visit attendance and see online supplementary Table 1 for numbers of missing data that were imputed). Missing data were imputed using information collected at study visits, annual follow-up telephone calls, community surveillance of hospitalizations, questionnaires administered to proxies, and covariates included in the main analytic model. For participants alive at the time of ARIC visit 4 or 5 but who did not attend the visit, scores were imputed at the median visit date. For participants who were deceased prior to ARIC visit 5, scores were imputed 6 months prior to death. Online supplementary Table 2 shows baseline characteristics of participants by vital status at visit 5 . We additionally assessed the impact of study attrition by comparing complete case analyses (defined in 2 ways: complete data at visit 2 and complete data at visit 2 and attended visits 2, 4, and 5) with imputation for covariates only and with imputation for covariates and cognitive test data among those alive at the time of visit 5 .

\section{Results}

The mean (SD) age of our population was 56.9 (6) years; $57 \%$ of participants were women, $24 \%$ of participants were black, and the mean (SD) $25(\mathrm{OH}) \mathrm{D}$ concentration was 24.3 (9) $\mathrm{ng} / \mathrm{mL}$ (Table 1). Compared to those with sufficient $(\geq 30 \mathrm{ng} / \mathrm{mL}) 25(\mathrm{OH}) \mathrm{D}$, those with deficient ( $<20 \mathrm{ng} / \mathrm{mL}) 25(\mathrm{OH}) \mathrm{D}$ were more likely to be women (68 vs. $49 \%, p<0.001$ ), were more likely to be black 
Table 1. Baseline characteristics of ARIC study participants, ARIC visit 2 (1990-1992)

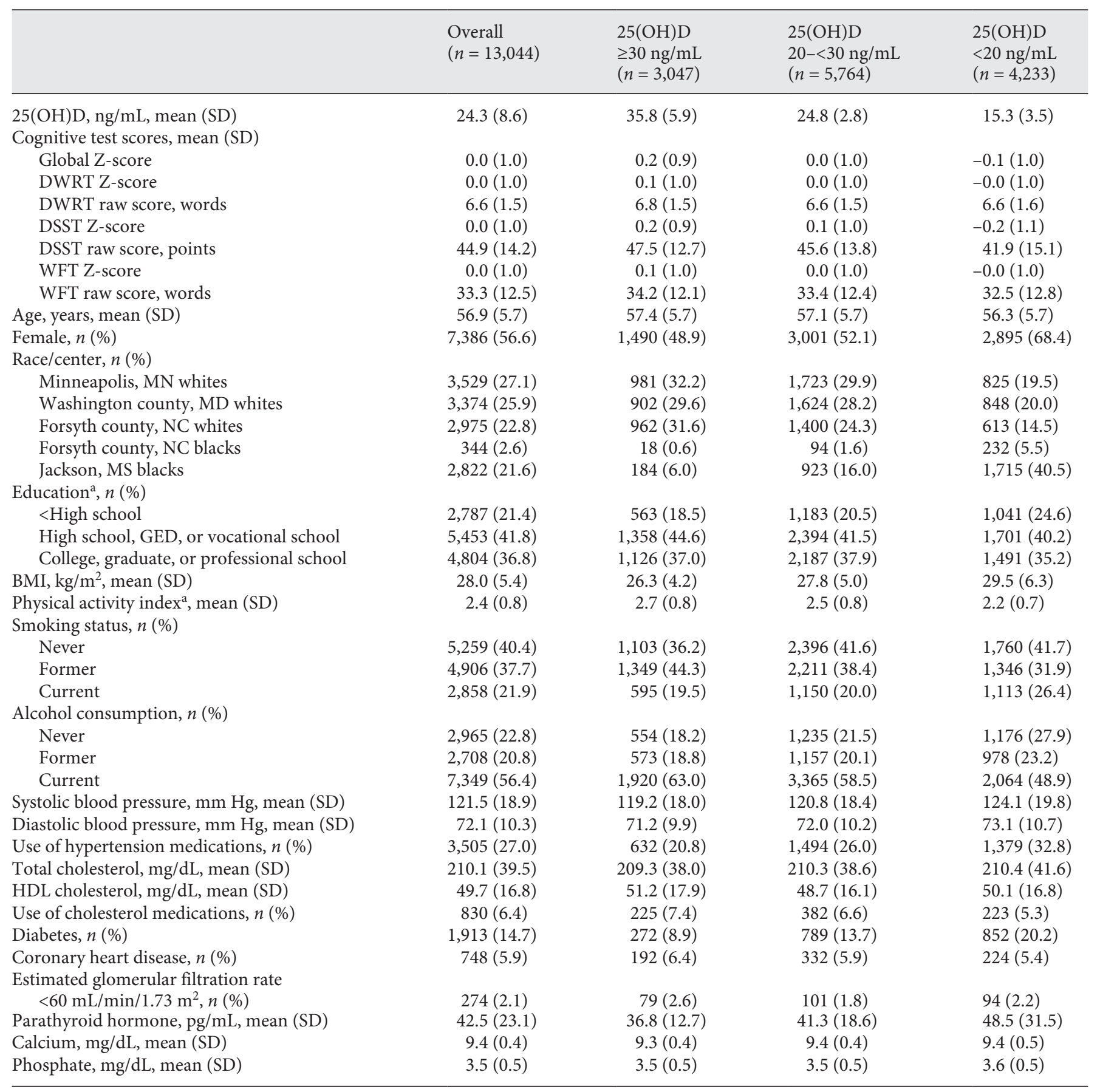

${ }^{a}$ Measured at ARIC visit 1 (1987-1989).

( 24 vs. $6 \%, p<0.001$ ), were slightly younger (56.3 vs. 57.4 years, $p<0.001$ ), and were more likely to have less than high school education (25 vs. $19 \%, p<0.001)$.

Participants in all three $25(\mathrm{OH}) \mathrm{D}$ categories experienced cognitive decline over follow-up. However, the 20-year cognitive decline was similar among participants with deficient $(<20 \mathrm{ng} / \mathrm{mL})$ and intermediate $(20-<30 \mathrm{ng} /$ $\mathrm{mL}) 25(\mathrm{OH}) \mathrm{D}$ concentrations compared to those with sufficient $(\geq 30 \mathrm{ng} / \mathrm{mL})$ concentrations (Table 2). In our primary adjusted model (Model 1), compared to those 
Table 2. Average adjusted 20 -year decline and difference in 20-year decline in global cognitive Z-score By 25(OH)D group, ARIC study (1990-1992 to 2011-2013)

\begin{tabular}{|c|c|c|c|c|c|}
\hline & \multicolumn{3}{|l|}{ 20-Year decline } & $\begin{array}{l}\text { Difference } 25(\mathrm{OH}) \mathrm{D} \\
20-<30 \text { vs. } \geq 30 \mathrm{ng} / \mathrm{mL}\end{array}$ & $\begin{array}{l}\text { Difference } 25(\mathrm{OH}) \mathrm{D} \\
<20 \text { vs. } \geq 30 \mathrm{ng} / \mathrm{mL}\end{array}$ \\
\hline Model 1 & $-0.748(-0.884$ to -0.612$)$ & $-0.777(-0.913$ to -0.641$)$ & $-0.783(-0.922$ to -0.644$)$ & $-0.029(-0.080$ to 0.023$)$ & $-0.035(-0.104$ to 0.033$)$ \\
\hline Model 2 & $-0.816(-0.962$ to -0.670$)$ & $-0.838(-0.984$ to -0.692$)$ & $-0.843(-0.994$ to -0.692$)$ & $-0.022(-0.073$ to 0.030$)$ & $-0.027(-0.095$ to 0.042$)$ \\
\hline Model 3 & $-0.808(-0.956$ to -0.660$)$ & $-0.830(-0.977$ to -0.682$)$ & $-0.839(-0.991$ to -0.687$)$ & $-0.022(-0.074$ to 0.030$)$ & $-0.031(-0.101$ to 0.039$)$ \\
\hline Model 2 & $-0.800(-0.957$ to -0.643$)$ & $-0.820(-0.977$ to -0.663$)$ & $-0.804(-0.969$ to -0.639$)$ & $-0.019(-0.072$ to 0.034$)$ & $-0.004(-0.078$ to 0.070$)$ \\
\hline Model 3 & $-0.808(-0.967$ to -0.649$)$ & $-0.826(-0.983$ to -0.669$)$ & $-0.812(-0.977$ to -0.647$)$ & $-0.018(-0.071$ to 0.035$)$ & $-0.004(-0.078$ to 0.070$)$ \\
\hline \multicolumn{6}{|c|}{ Blacks $(n=3,166)$} \\
\hline Model 1 & $-0.729(-1.066$ to -0.392$)$ & $-0.830(-1.114$ to -0.546$)$ & $-0.864(-1.136$ to -0.592$)$ & $-0.101(-0.303$ to 0.101$)$ & $-0.135(-0.337$ to 0.067$)$ \\
\hline Model 2 & $-0.780(-1.129$ to -0.431$)$ & $-0.877(-1.175$ to -0.579$)$ & $-0.908(-1.194$ to -0.622$)$ & $-0.096(-0.298$ to 0.106$)$ & $-0.128(-0.330$ to 0.074$)$ \\
\hline Model 3 & $-0.736(-1.087$ to -0.385$)$ & $-0.833(-1.133$ to -0.533$)$ & $-0.877(-1.165$ to -0.589$)$ & $-0.097(-0.299$ to 0.105$)$ & $-0.141(-0.343$ to 0.061$)$ \\
\hline
\end{tabular}

${ }^{a}$ Model 1, demographic, behavioral/socioeconomic, and genetic variables including: age, age ${ }^{2}$, gender, race/center (in overall model) or center (in race-stratified models), education, body mass index, smoking status, physical activity, and apolipoprotein $\epsilon 4$ genotype, and interactions between each of these variables and time.

Model 2, model 1 + cardiovascular factors including: systolic blood pressure, use of hypertension medication, total cholesterol, HDL cholesterol, use of cholesterol medications, diabetes, coronary heart disease, estimated glomerular filtration rate, and interactions between each of these variables and time.

Model 3, model $2+$ biomarker mediators in the metabolic pathway including: parathyroid hormone, calcium, phosphorus, and interactions between each of these variables and time.

with sufficient $25(\mathrm{OH}) \mathrm{D}(\geq 30 \mathrm{ng} / \mathrm{mL})$, the difference in global cognitive Z-scores was -0.029 ( $95 \%$ CI -0.080 to $0.023)$ for intermediate $(20-<30 \mathrm{ng} / \mathrm{mL})$ and $-0.035(95 \%$ CI -0.104 to 0.033$)$ for deficient $(<20 \mathrm{ng} / \mathrm{mL}) 25(\mathrm{OH}) \mathrm{D}$. Further models adjusting for potential mediators (Model 2 ) and for biomarkers in the metabolic pathway (Model 3) did not appreciably alter our results.

Results were similar when we conducted complete case analyses, imputation for covariates only, and imputation for covariates and outcomes among those alive at the time of visit 5 (online suppl. Table 3 ).

There appeared to be potential differences in the magnitude of association by race with blacks having approximately 10 times greater decline in composite cognitive $Z$-score than whites comparing those with deficient $(<20$ $\mathrm{ng} / \mathrm{mL})$ to those with sufficient $(\geq 30 \mathrm{ng} / \mathrm{mL}) 25(\mathrm{OH}) \mathrm{D}$ (Model 1: blacks -0.135 [95\% CI -0.337 to 0.067 ], whites -0.011 [ $95 \%$ CI -0.085 to 0.063 ]; Table 2). However, the formal test for interaction by race was not significant $(p$ interaction $=0.45$ ) in our main model (Model 1$)$ imputing for covariates and outcomes. As shown in online supplementary Table 3 , the complete case analyses for blacks showed greater cognitive decline in the deficient $(<20 \mathrm{ng} /$ $\mathrm{mL}) 25(\mathrm{OH}) \mathrm{D}$ group compared to the sufficient $(\geq 30 \mathrm{ng} /$ $\mathrm{mL}) 25(\mathrm{OH}) \mathrm{D}$ group (i.e., among those with complete data at visit 2: -0.214 [95\% CI -0.406 to -0.023$]$ and among those with complete data at visit 2 and who attended visits 2,4 , and $5:-0.230$ [ -0.441 to -0.019$]$ ), but this trended back to the null after accounting for attrition in the full imputation model.

Neither were there differences in 6-year (time between ARIC visits 2 and 4 ) and 14-year (time between ARIC visits 4 and 5) cognitive decline in composite cognitive $Z$ score between $25(\mathrm{OH}) \mathrm{D}$ categories, nor was there any difference found when using alternate $25(\mathrm{OH}) \mathrm{D}$ cut-points of 10 and $20 \mathrm{ng} / \mathrm{mL}$ (all $p>0.05$; online suppl. Tables 4-6).

In sensitivity analyses where participants scoring worse than $-2 \mathrm{SD}$ on the baseline composite cognitive Zscore were excluded, results remained similar with no difference in 20-year cognitive decline in composite cognitive $Z$-score between $25(\mathrm{OH}) \mathrm{D}$ categories ( $p>0.05$ ) (online suppl. Table 7).

\section{Discussion}

In this community-based population of 13,044 white and black individuals, lower concentrations of $25(\mathrm{OH}) \mathrm{D}$ measured in midlife were not significantly associated with more rapid cognitive decline over a 20 -year of follow-up compared to higher concentrations of $25(\mathrm{OH}) \mathrm{D}$. Our results suggest that low midlife concentrations of 
$25(\mathrm{OH}) \mathrm{D}$ in whites and blacks are not a risk factor for long-term cognitive dysfunction.

The findings of this study are consistent with our prior work in a smaller population with less follow-up time [8] and with other studies [9-11] that reported no association of low $25(\mathrm{OH}) \mathrm{D}$ concentrations with cognitive decline. There has been heterogeneity in the results of prior studies - with significant associations typically found in analyses conducted among older populations with shorter follow-up [2-7], and nonsignificant results were typically reported in younger populations with longer followup [8-11]. However, there was one recent Swedish study of 1,182 older white men (mean age 71 years) that also found no association of $25(\mathrm{OH}) \mathrm{D}$ concentrations with cognitive decline over a long term (18-year) of follow-up [12]. Here, we provide evidence for a lack of association between $25(\mathrm{OH}) \mathrm{D}$ and cognitive decline in a much larger sample $(n=13,044)$ of both white and black racial groups who were followed since mid-life.

It is possible that the previously reported associations between $25(\mathrm{OH}) \mathrm{D}$ concentrations and cognitive impairment are a result of reverse causation - whereby low $25(\mathrm{OH}) \mathrm{D}$ is a marker of poor health (resulting from those in poor health [e.g., those with cognitive impairment] doing less physical activity and having less sun exposure and thereby having lower vitamin $\mathrm{D}$ concentrations) rather than a causative factor in cognitive impairment and dementia pathogenesis. Our study is less susceptible to reverse causation as $25(\mathrm{OH}) \mathrm{D}$ was measured in midlife and cognitive change was evaluated over 20 -year. Further, in sensitivity analyses, we excluded individuals with a composite cognitive $Z$-score less than $-2 \mathrm{SD}$ at baseline to further remove effects of prevalent cognitive impairment at baseline. Additionally, a recent Mendelian randomization study found that genetically determined $25(\mathrm{OH}) \mathrm{D}$ also was not associated with cognitive function [30], which also supports the lack of causal relationship.

Certain limitations should be considered in the interpretation of our results. First, we only had a single measurement of $25(\mathrm{OH}) \mathrm{D}$, which has been shown to vary over time within individuals $[16,31,32]$. Second, our study had attrition due to death and loss to follow-up over the approximately 20 -year of follow-up. However, we attempted to account for attrition using multiple imputation methods that were previously validated in the ARIC cohort [29], but it is important to note that these methods may not have fully accounted for the effects of loss to follow-up of the participants in our study. Third, although our population consisted of over 3,000 black participants, our race-specific analyses may be underpowered to detect an association. Finally, although we had cognition measured at 3 time points over a median of 20 years, the neuropsychological assessments were not comprehensive assessments of all cognitive domains.

On the other hand, our study importantly has a number of strengths, including a large sample of $>13,000$ black and white adults followed long-term for approximately 20 years. We also had comprehensive measurement of important confounders. Further, the measurement of $25(\mathrm{OH})$ $\mathrm{D}$ in midlife, approximately 20 years prior to the end of follow-up, helped to address the issue of reverse causation in the association between $25(\mathrm{OH}) \mathrm{D}$ and cognitive decline.

In conclusion, in this study of $>13,000$ white and black participants, there was no association between midlife $25(\mathrm{OH}) \mathrm{D}$ concentration and cognitive decline over 20 years. The results suggest that prior studies performed in elderly populations may have been biased by reverse causation. The results also suggest that there may not be a role for vitamin $\mathrm{D}$ supplementation in preventing or slowing cognitive decline; however, only randomized controlled trials can come to this conclusion definitively.

\section{Acknowledgments}

The authors acknowledge and thank the participants and staff for their important contribution to the ARIC study.

\section{Disclosure Statement}

Dr. Knopman serves on a Data Safety Monitoring Board for Lundbeck Pharmaceuticals and for the DIAN study. Dr. Knopman is also an investigator in clinical trials sponsored by the Alzheimer's Disease Cooperative Study, TauRX Pharmaceuticals, and Lilly Pharmaceuticals.

\section{Funding Source}

This work was supported by grant R01NS072243 from NIH/ NINDS to Dr. Erin D. Michos, by grant R01HL103706 from NIH/ NHLBI to Dr. Pamela L. Lutsey, and by grant R01HL103706-S1 from the National Institutes of Health Office of Dietary Supplements to Dr. Pamela L. Lutsey. Additionally, Drs. Di Zhao and Erin D. Michos are supported by the Blumenthal Scholars Fund at Johns Hopkins for preventive cardiology research. Dr. Andrea L.C. Schneider is supported by the NIH/NINDS via an administrative supplement to award R25NS065729. The ARIC Study is collaboratively funded by NIH/NHLBI contracts HHSN268201100005C, HHSN268201100006C, HHSN268201100007C, HHSN268201100008C,HHSN268201100009C,HHSN268201100010C, HHSN268201100011C, and HHSN268201100012C. ARIC-NCS was funded by U01 HL096812, HL096814, HL096899, HL096902, and HL096917, with additional NIH/NINDS support. 


\section{References}

1 Holick MF, Binkley NC, Bischoff-Ferrari HA, Gordon CM, Hanley DA, Heaney RP, et al: Evaluation, treatment, and prevention of vitamin D deficiency: an Endocrine Society clinical practice guideline. J Clin Endocrinol Metab 2011;96:1911-1930.

2 van der Schaft J, Koek HL, Dijkstra E, Verhaar HJ, van der Schouw YT, Emmelot-Vonk MH: The association between vitamin $\mathrm{D}$ and cognition: a systematic review. Ageing Res Rev 2013;12:1013-1023.

3 Miller JW, Harvey DJ, Beckett LA, Green R, Farias ST, Reed BR, et al: Vitamin D status and rates of cognitive decline in a multiethnic cohort of older adults. JAMA Neurol 2015;72:1295-1303.

4 Toffanello ED, Coin A, Perissinotto E, Zambon S, Sarti S, Veronese N, et al: Vitamin D deficiency predicts cognitive decline in older men and women: The Pro.V.A. Study. Neurology 2014;83:2292-2298.

5 Matchar DB, Chei CL, Yin ZX, Koh V, Chakraborty B, Shi XM, et al: Vitamin D levels and the risk of cognitive decline in Chinese elderly people: the Chinese longitudinal healthy longevity survey. J Gerontol A Biol Sci Med Sci 2016;71:1363-1368.

6 Perna L, Mons U, Kliegel M, Brenner H: Serum 25-hydroxyvitamin $\mathrm{D}$ and cognitive decline: a longitudinal study among non-demented older adults. Dement Geriatr Cogn Disord 2014;38:254-263.

7 Slinin Y, Paudel M, Taylor BC, Ishani A, Rossom R, Yaffe K, et al: Association between serum $25(\mathrm{OH})$ vitamin $\mathrm{D}$ and the risk of cognitive decline in older women. J Gerontol A Biol Sci Med Sci 2012;67:1092-1098.

8 Schneider AL, Lutsey PL, Alonso A, Gottesman RF, Sharrett AR, Carson KA, et al: Vitamin $\mathrm{D}$ and cognitive function and dementia risk in a biracial cohort: the ARIC Brain MRI Study. Eur J Neurol 2014;21:1211-1218, e69e70.

9 Bartali B, Devore E, Grodstein F, Kang JH: Plasma vitamin D levels and cognitive function in aging women: the nurses' health study. J Nutr Health Aging 2014;18:400-406.

10 Overman MJ, Pendleton N, O'Neill TW, Bartfai G, Casanueva FF, Finn JD, et al: Evaluation of cognitive subdomains, 25-hydroxyvitamin $\mathrm{D}$, and 1,25-dihydroxyvitamin D in the European Male Ageing Study. Eur J Nutr 2017;56:2093-2103.

11 van Schoor NM, Comijs HC, Llewellyn DJ, Lips P: Cross-sectional and longitudinal as- sociations between serum 25-hydroxyvitamin $\mathrm{D}$ and cognitive functioning. Int Psychogeriatr 2016;28:759-768.

12 Olsson E, Byberg L, Karlstrom B, Cederholm T, Melhus H, Sjogren P, et al: Vitamin D is not associated with incident dementia or cognitive impairment: an 18-y follow-up study in community-living old men. Am J Clin Nutr 2017;105:936-943.

13 Ashwell M, Stone EM, Stolte H, Cashman KD, Macdonald H, Lanham-New S, et al: UK Food Standards Agency Workshop Report: an investigation of the relative contributions of diet and sunlight to vitamin $\mathrm{D}$ status. $\mathrm{Br} \mathrm{J}$ Nutr 2010;104:603-611.

14 Lutsey PL, Eckfeldt JH, Ogagarue ER, Folsom AR, Michos ED, Gross M: The 25-hydroxyvitamin D3 C-3 epimer: distribution, correlates, and reclassification of 25-hydroxyvitamin D status in the population-based Atherosclerosis Risk in Communities Study (ARIC). Clin Chim Acta 2015;442:75-81.

15 Agborsangaya C, Toriola AT, Grankvist K, Surcel HM, Holl K, Parkkila S, et al: The effects of storage time and sampling season on the stability of serum 25-hydroxy vitamin D and androstenedione. Nutr Cancer 2010;62:5157.

16 Kasahara AK, Singh RJ, Noymer A: Vitamin D (25OHD) Serum Seasonality in the United States. PLoS One 2013;8:e65785.

17 Looker AC, Dawson-Hughes B, Calvo MS, Gunter EW, Sahyoun NR: Serum 25-hydroxyvitamin D status of adolescents and adults in two seasonal subpopulations from NHANES III. Bone 2002;30:771-777.

18 Ross AC, Manson JE, Abrams SA, Aloia JF, Brannon PM, Clinton SK, et al: The 2011 report on dietary reference intakes for calcium and vitamin D from the Institute of Medicine: what clinicians need to know. J Clin Endocrinol Metab 2011;96:53-58.

19 Knopman DS, Ryberg S: A verbal memory test with high predictive accuracy for dementia of the Alzheimer type. Arch Neurol 1989;46:141145.

20 Wechsler D: Wechsler Adult Intelligence Scale-Revised (WAIS-R) Manual. New York, Psychological Corp, 1987.

21 Benton AL, Hamsher K: Multilingual Aphasia Examination, ed 2. Iowa City, AJA Associates, 1989.

22 Rawlings AM, Sharrett AR, Schneider AL, Coresh J, Albert M, Couper D, et al: Diabetes in midlife and cognitive change over 20 years: a cohort study. Ann Intern Med 2014; 161:785-793

23 Gottesman RF, Rawlings AM, Sharrett AR, Albert M, Alonso A, Bandeen-Roche K, et al: Impact of differential attrition on the association of education with cognitive change over 20 years of follow-up: the ARIC neurocognitive study. Am J Epidemiol 2014;179:956-966.

24 The Atherosclerosis Risk in Communities (ARIC) Study: design and objectives. The ARIC investigators. Am J Epidemiol 1989; 129:687-702

25 Baecke JA, Burema J, Frijters JE: A short questionnaire for the measurement of habitual physical activity in epidemiological studies. Am J Clin Nutr 1982;36:936-942.

26 Pugliese G, Solini A, Bonora E, Orsi E, Zerbini G, Giorgino F, et al: The chronic kidney disease epidemiology collaboration (CKDEPI) equation provides a better definition of cardiovascular burden associated with CKD than the modification of diet in renal disease (MDRD) study formula in subjects with type 2 diabetes. Atherosclerosis 2011;218:194199.

27 Chambless LE, Folsom AR, Sharrett AR, Sorlie P, Couper D, Szklo M, et al: Coronary heart disease risk prediction in the Atherosclerosis Risk in Communities (ARIC) study. J Clin Epidemiol 2003;56:880-890.

28 White IR, Royston P, Wood AM: Multiple imputation using chained equations: Issues and guidance for practice. Stat Med 2011;30:377399.

29 Rawlings AM, Sang Y, Sharrett AR, Coresh J, Griswold M, Kucharska-Newton AM, et al: Multiple imputation of cognitive performance as a repeatedly measured outcome. Eur J Epidemiol 2017;32:55-66.

30 Maddock J, Cavadino A, Power C, Hypponen E; VDCS Group: Vitamin D and cognition: findings from a Mendelian Randomisation Study. Faseb J 2015;29.

31 Jorde R, Sneve M, Hutchinson M, Emaus N, Figenschau Y, Grimnes G: Tracking of serum 25-hydroxyvitamin D levels during 14 years in a population-based study and during 12 months in an intervention study. Am J Epidemiol 2010;171:903-908.

32 Berger C, Greene-Finestone LS, Langsetmo L, Kreiger N, Joseph L, Kovacs CS, et al: Temporal trends and determinants of longitudinal change in 25-hydroxyvitamin D and parathyroid hormone levels. J Bone Min Res 2012;27:1381-1389. 